\title{
DESCRIPTION OF TWO NEW SPECIES OF ENCYRTIDAE (HYMENOPTERA: CHALCIDOIDEA) FROM TAMIL NADU, INDIA
}

\section{Sagadai Manickavasagam ${ }^{1}$ \& Anandan Rameshkumar ${ }^{2}$}

${ }^{1}$ Parasitoid Taxonomy and Biocontrol Laboratory, Department of Entomology, Faculty of Agriculture, Annamalai University Chidambaram, Tamil Nadu 608002, India

${ }^{2}$ Insect Biosystematics Wing, National Bureau of Agriculturally Important Insects, Hebbal, Bengaluru, Karnataka 560024, India ${ }^{1}$ drmanicks2003@yahoo.co.in (corresponding author), 2drrameshtrichy@gmail.com

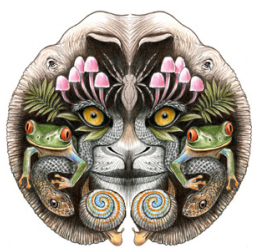

ISSN

Online 0974-7907

Print 0974-7893

OPEN ACCESS
Abstract: Two new encyrtid species, Adektitopus hayati and Rhopus tamilanus parasitizing mealybugs are described from Tamil Nadu, India.

Keywords: Adektitopus, India, new species, Rhopus.

Noyes \& Hayat (1984) erected the genus Adektitopus with $A$. gordhi as the type species. Later, Hayat (1989) transferred Clausenia longipennis Shafee \& Avasthi (1983) to Adektitopus. These two species known from this genus are reported so far only from India. Hayat (2006) gave a key to these two species along with one undetermined species. From the routine survey for encyrtids in Tamil Nadu, specimens apparently belonging to this undetermined species of Adektitopus were recovered and is described here as a new species. Another new species, belonging to the cosmopolitan genus Rhopus Förster, which is represented by 62 species globally with 20 and 18 species from Oriental and India respectively (Noyes 2012) which are parasitoids of mealybugs associated with grasses (Graminae) (Noyes \& Hayat 1994) including rice, is also described.

\section{Material and Methods}

The specimens of Adektitopus were collected by a sweep net and in yellow pan trap in grassy field, whereas
Rhopus specimens were host reared from an unidentified grass mealybug from Annamalai University premises. The specimens were processed using Hexamethyldisilazane (HMDS) and mounted on cards. Some specimens were dissected and mounted on slides in Canada balsam. All the photographs were taken with either Leica DM750 phase contrast microscope or Leica S8APO stereozoom microscope with montage and CombineZP softwares.

Adektitopus hayati sp. nov.

(Images 1-5)

urn:Isid:zoobank.org:act:EFE6E592-9CA0-4F10-ACE3-AB682417238C

\section{Material examined \\ Holotype: EDAU/Enc4/2012, 17.viii.2011, female (EDAU) on card, labelled "Adektitopus hayati}

Abbreviations: F1-6 - funicle segments 1-6; POL - minimum distance between the posterior ocellli; OOL - miniumum distance between a posterior ocellus and eye margin; $\mathrm{OCL}$ - minimum distance between a posterior ocellus and occipital margin; AOL - minimum distance between a posterior ocellus and the anterior ocellus; T1 \& T2 - gastral tergites 1 \& 2. EDAU - Entomology Department, Annamalai University, Parasitoid Taxonomy and Biocontrol Laboratory, Faculty of Agriculture, Chidambaram, Tamil Nadu; NBAll - National Bureau of Agriculturally Important Insects, Bengaluru; ZDAMU - Insect Collection, Department of Zoology, Aligarh Muslim University, Aligarh, Uttar Pradesh.

DOI: http://dx.doi.org/10.11609/JoTT.03306.3642-45 | ZooBank: urn:Isid:zoobank.org:pub:F24C60B3-A841-4E5C-AC6E-8DA4CA449834

Manuscript details: Ms \# 03306 | Received 15 August 2012 | Final received 16 November 2012 | Finally accepted 07 February 2013

Citation: Manickavasagam, S. \& A. Rameshkumar (2013). Description of two new species of Encyrtidae (Hymenoptera: Chalcidoidea) from Tamil Nadu, India. Journal of Threatened Taxa 5(2): 3642-3645; doi:10.11609/JoTT.03306.3642-45

Copyright: (c) Manickavasagam \& Rameshkumar 2013. Creative Commons Attribution 3.0 Unported License. JoTT allows unrestricted use of this article in any medium, reproduction and distribution by providing adequate credit to the authors and the source of publication.

Funding: University Grants Commission, New Delhi UGC file no.34-225/2008 (SR) dt. 31.12.2008

Competing Interest: None.

Acknowledgements: The authors are thankful to Dr. John S. Noyes of Natural History Museum, London and Dr. Md. Hayat of Aligarh Muslim University

Uttar Pradesh for their help in confirming the identity of encyrtids. The financial assistance by the University Grants Commission, Government of India, New Delhi, through major research project to carry out the survey is gratefully acknowledged. 

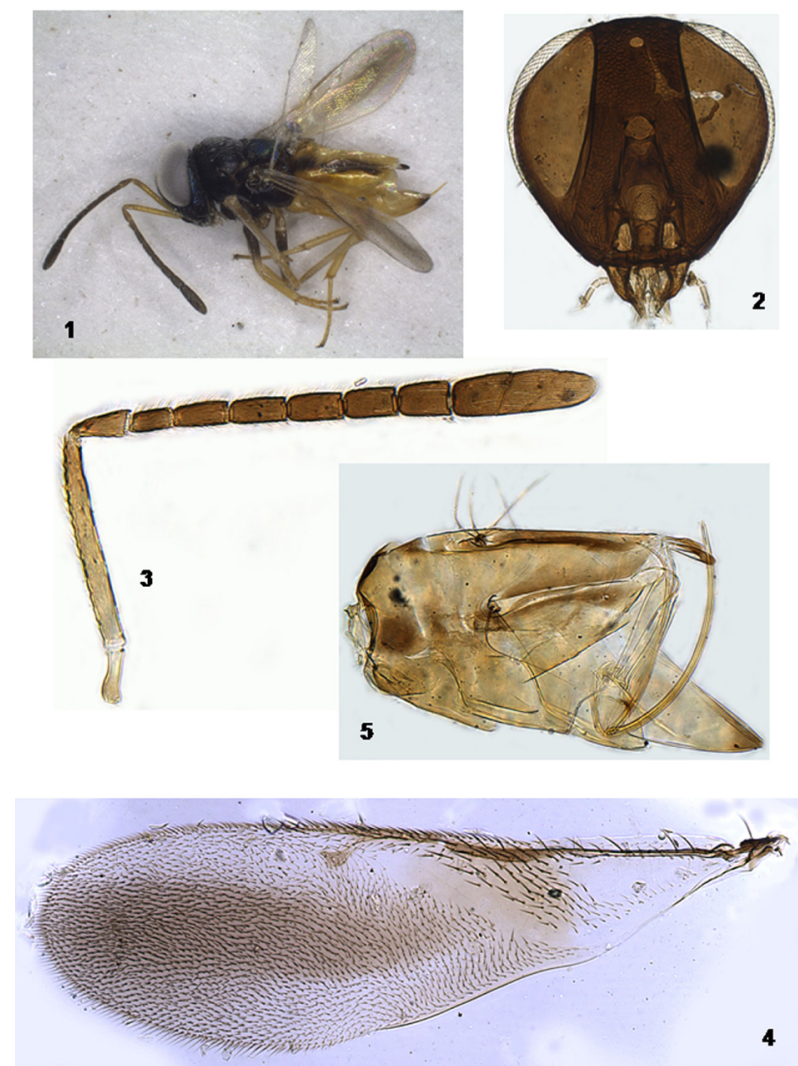

Images 1-5. Adektitopus hayati sp. nov.

1 - female habitus; 2 - head frontal view; 3 - antenna; 4 - fore wing; 5 - Metasoma with ovipositor.

Manickavasagam \& Rameshkumar", grassy field, Malaise trap, AnnamalaiUniversity premises, Chidambaram, Tamil Nadu, India $\left(11.23^{\circ} \mathrm{N} \& 79.41^{\circ} \mathrm{E}\right)$, coll. Manickavasagam \& Rameshkumar.

Paratypes: 12.i.2012, 11 females, Seven females (6 on card and 1 on slide under five coverslips) with same data as in Holotype (EDAU); EDAU/Enc4P1/2012 - EDAU/ Enc4P7/2012, 4 females, yellow pan traps, grassy field, Annamalai University premises, Chidambaram $\left(11.23^{\circ} \mathrm{N}\right.$ \& 79.41 ${ }^{\circ} \mathrm{E}$ ), coll. Rameshkumar \& Palanivel (two females each with ZDAMU - HYM.CH.665 and NBAIl - DNR/Reg. No.1/3a/2012 \& DNR/Reg.No.1/3b/2012, Bengaluru).

Female: (Image 1). Length, 1.3-1.7mm. (Holotype, $1.6 \mathrm{~mm})$.

Colour: Head black with metallic violet luster; antennal scape yellow progressively darkening towards apex, apical one-fourth brown; pedicel yellowish-brown; flagellum dark brown. Pronotum and mesoscutum dark brown with metallic purplish luster; tegula largely and axilla dark brown; scutellum basally dark purple, gradually becoming green and then yellowish-green at apex; propodeum brown; mesopleuron dark brown. Forewing subhyaline with a broad longitudinal infuscate patch from proximal end of marginal vein to apex and also below parastigma; hindwing subhyaline. Legs with fore and mid coxae, trochanters and major part of femora dark brown; apices of femora and remainder of legs and whole of hind leg yellowish-brown. Metasoma largely yellowish with light brown tinge except the last tergite, dorso-lateral sides of first tergite, tip of hypopygium and exserted part of ovipositor sheath dark brown.

Head: (Image 2) Head, in front view, slightly broader than high (570:530); frontovertex one-third head width; frontovertex with reticulate sculpture; setae on head, eye and malar space white; eye length $3.5 \times$ malar space; antennal scrobes not meeting dorsally; antennal toruli separated from each other by their own height and separated from mouth margin by less than their own length. Antenna (Image 3) with scape cylindrical and $8.5 \times$ as long as broad; pedicel longer than F1; all funicle segments longer than broad; clava 3-segmented and apically rounded with 13 longitudinal sensillae, slightly shorter than preceding three funicle segments combined. Mandible tridentate.

Relative measurements (in microns): Head width, 570; height, 530; frontovertex width, 190; POL, 90; AOL, 50; OOL, 20; OCL, 40; eye height, 420; malar space, 120; antennal toruli width, 40; distance between toruli, 70; scape length, 340; scape width, 40.

Mesosoma: Mesoscutum with shallow squamiformreticulate sculpture; axilla and scutellum with very much deep vermiculate - reticulate sculpture; setae on mesoscutum white, setae on pronotum, axilla, and scutellum whitish with base light brown, a pair of long setae at apex of scutellum brown. Forewing $3.25 \times$ as long as wide (1300:400) (Image 4); hind wing 5.4x as long as wide.

Relative measurements (in microns): Mesosoma length, 670; mesoscutum length, 290; scutellum length, 240; median length of propodeum, 80; fore wing length, 1300; width, 400; submarginal vein length, 480; marginal vein length, 140; post marginal vein length, 110; stigmal vein length, 60; hind wing length, 970; width, 180; mid tibia length, 610; mid tibial spur length, 160.

Metasoma: (Image 5) Longer than mesosoma (850: 700); gasteral tergites with shallow reticulate sculpture (visible at higher magnifications); ovipositor exserted and $1.15 \times$ as long as mid tibial length, $4.3 \times$ as long as mid tibial spur.

Relative measurements (in microns): metasoma length, 850; last tergite length, 520; ovipositor length, 690; gonostylus length, 140.

Male: Unknown.

Variation: Colour variation is noted from gradual 
darkening of pedicel and flagellum to complete dark brown. Similar colour variation is also noted in the apex of scape.

Host: Unknown.

Distribution: India: Tamil Nadu (Chidambaram).

Etymology: The species is named after the chalcid specialist, Dr. M. Hayat of Aligarh Muslim University, Aligarh, Uttar Pradesh. The name is noun in genitive case.

Comments: This new species is closer to Adektitopus gordhi but differs in the following characters: forewing $3.25 \times$ as long as wide; distinct broad longitudinal infuscate patch / streak from level of proximal end of marginal vein to nearly the apex; head width $1.05 \times$ its height; ovipositor $1.15 \times$ as long as mid tibia length and coloration of legs, testaceous yellow with fore and mid coxae, femora except apices dark brown [In gordhi, fore wing slightly less than $3 \times$ as long as wide; fore wing hyaline, rarely with a faint longitudinal fuscous streak in apical half; head width $1.12 \times$ its height; ovipositor $1.33 \times$ as long as mid tibia length; legs honey yellow except fore coxa and largely mid coxa dark brown.].

\section{Rhopus tamilanus sp. nov.}

(Images 6-13)

urn:Isid:zoobank.org:act:9D14FF64-CE84-451D-B40E-6C3FEA195CFC

\section{Material examined}

Holotype: EDAU/Enc5/2012m, 12.ix.2009, female (EDAU) on card labelled "Rhopus tamilanus Manickavasagam \& Rameshkumar", reared from unidentified mealy bug on grass, Annamalai University campus, Chidambaram, Cuddalore, Tamil Nadu, India $\left(11.23^{\circ} \mathrm{N} \& 79.41^{\circ} \mathrm{E}\right)$, coll. Manickavasagam \& Rameshkumar.

Paratypes: 3 females on slide under four cover slips with same data as in holotype (1 with NBAll DNR/Reg. no.1/4/2012 and 2 with EDAU: EDAU/Enc5P1/2012).

Female (Image 6). Holotype. Length $0.8 \mathrm{~mm}$.

Colour: Head orange except area below toruli yellowish; genae pale brown; radicle, scape and pedicel pale yellow; flagellum uniformly brown. Pronotum yellowish with black tinge; mesoscutum uniformly yellow except a narrow parallel blackish patch at the base; axill and basal half of scutellum yellowish, apical half and border blackish; propodeum yellowish; part of mesopleuron blackish; venter of mesosoma pale yellow. Forewing with a pale but distinct infuscation below distal half of venation. Legs uniformly pale yellow except part of outer coxae blackish. Gaster with T1 basally yellow; apex of $\mathrm{T} 1$ and base of $\mathrm{T} 2$ pale black, remainder of the
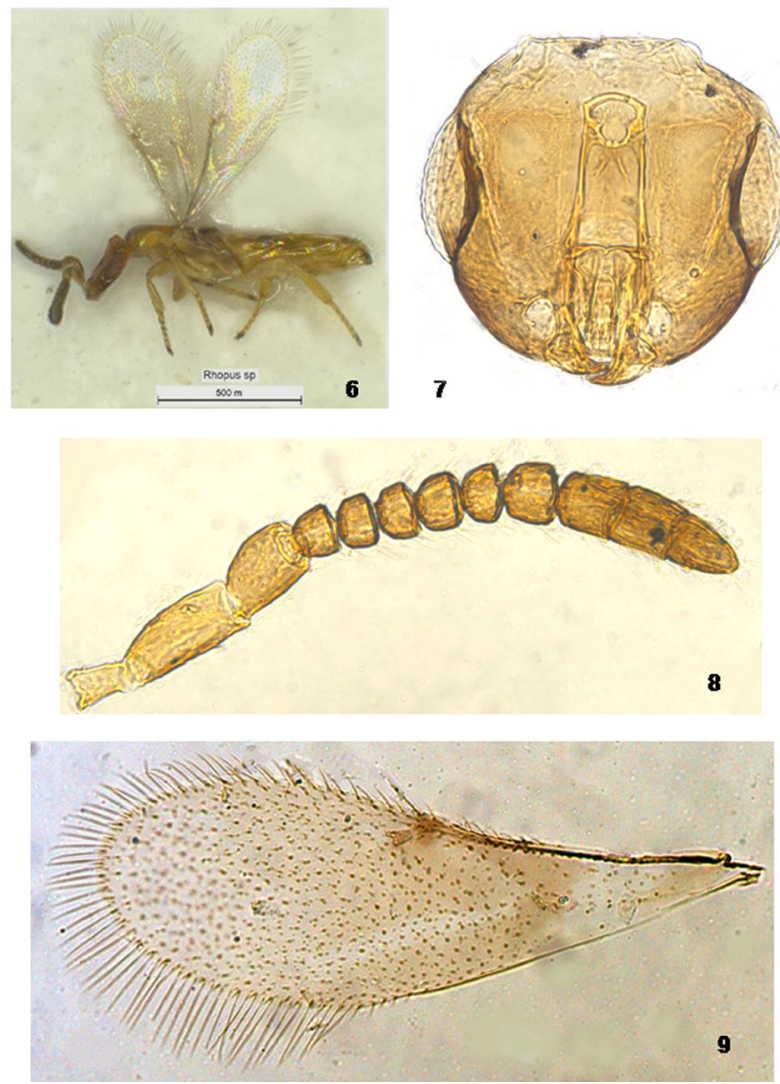

Images 6-9. Rhopus tamilanus sp. nov.

6 - female habitus; 7 - head frontal view; 8 - antenna; 9 - fore wing.

metasoma yellow; venter of metasoma uniformly pale yellow except brown apex of hypopygium.

Head: (Image 7) Almost as broad as high (210:200); frontovertex width $0.75 \times$ head width. Antenna (Image 8 ) with scape $2.2 \times$ as long as broad; pedicel slightly broader than scape (28:25); all funicle segments broader than long with one longitudinal sensilla each; F2 and F3 subequal in length; F1, F4 and F5 equal; F6 larger than F5; clava 3-segmented and longer than preceding four funicle segments combined (83:75); clava with 10 longitudinal sensillae.

Relative measurements (in microns): Head width, 210; head height, 200; frontovertex width, 150; POL, 80; AOL, 40; OOL, 50; OCL, 10; eye height, 90; malar space, 80; distance between toruli, 46; torulus length, 24; torulus width, 19; length : width of antennal segments - scape length, 60; width, 30; pedicel length, 40; width, 30 ; length and width of F1, $18: 20 ; F 2,15: 22 ; F 3,15$ : 25; F4, $18: 25$; F5, $18: 25$; F6, $25: 28$; clava length, 83.

Mesosoma: (Image 11) Shorter than metasoma (300:410). Pronotum, mesoscutum and scutellum with two, two and six pairs of setae respectively. Forewing $2.9 \times$ as long as broad (Image 9); marginal fringe $0.4 \times$ 

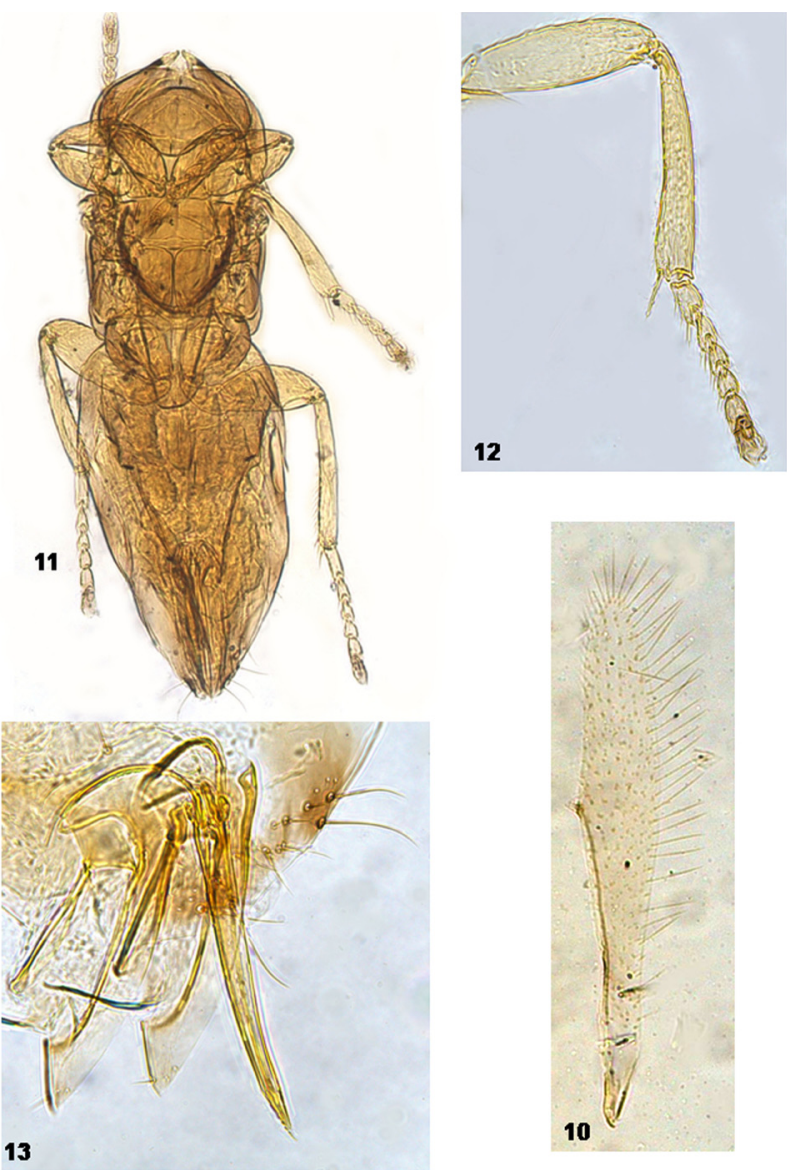

Images 10-13. Rhopus tamilanus sp.nov.

10 - hind wing; 11 - meso and metasoma dorsal view;

12 - leg showing mid tibia; 13 - ovipositor.

wing width; hindwing $8 \times$ as long as broad (Image 10); marginal fringe equal to wing width. Mid tibial spur longer than mid basitarsus (33:25) (Image 12), but equal to hind basitarsus; hind tibia with dense cilia on the ventral side.

Relative measurements (in microns): pronotum length, 23; mesoscutum length, 130; scutellum length, 113; fore wing length, 570; fore wing width, 200; marginal fringe length, 70; hind wing length, 480; hind wing width, 60; marginal fringe length, 60; mid tibia length, 148; mid tibial spur length, 33; mid basitarsus length, 25; hind tibia length, 163; hind basitarsus length, 33.
Metasoma: Ovipositor not exserted and $1.26 \times$ as long as mid tibia (187:148) (Image 13) and 5.3x as long as mid tibial spur.

Relative measurements (in microns): metasoma length, 410; ovipositor length, 187.

Male: Unknown.

Host: Unidentified grass mealybug (Hemiptera: Pseudococcidae).

Distribution: India: Tamil Nadu.

Etymology: This new species is named after the Indian state from which types were collected.

Comments: This species is closer to Rhopus aligarhensis (Shamim \& Shafee) and can be differentiated from it based on the following characters: Head as broad as height (1.05x); all funicle segments slightly broader than long; fore wing $2.9 \times$ as long as broad with a pale but distinct infuscation below distal half of venation; marginal fringe $0.4 \times$ of wing width; hind wing $8 \times$ as long as broad; ovipositor length $1.26 \times$ as long as mid tibial length [In $R$. aligarhensis, head $1.4 \times$ as broad as high; all funicle segments subquadrate; fore wing slightly infuscate, $2.4 \times$ as long as broad and marginal fringe 0.12 of wing width; hind wing $4.84 \times$ as long as broad; ovipositor length $1.40 \times$ as long as mid tibial length. Based upon the redescription given by Noyes \& Hayat, 1994.]

\section{REFERENCES}

Hayat, M. (1989). Taxonomic notes on Indian Encyrtidae (Hymenoptera: Chalcidoidea). IV. Oriental Insects 23: 275-285.

Hayat, M. (2006). Indian Encyrtidae (Hymenoptera: Chalcidoidea). Published by M. Hayat, Aligarh Muslim University, India, viii+496pp. Noyes, J.S. (2012). Universal Chalcidoidea Database. World Wide Web electronic publication. http://www.nhm.ac.uk/chalcidoids (accessed on 10 December 2012).

Noyes, J.S. \& M. Hayat (1984). A review of the genera of Indo-Pacific Encyrtidae (Hymenoptera: Chalcidoidea). Bulletin of the British Museum (Natural History) (Entomology) 48: 131-395.

Noyes, J.S. \& M. Hayat (1994). Oriental Mealybug Parasitoids of the Anagyrini (Hymenoptera: Encyrtidae). CAB International, Wallingford, Oxon, vii+554pp.

Shafee, S.A. \& R.K. Avasthi (1983). First record of Clausenia Ishii (Hymenoptera : Encyrtidae) from India with descriptions of two new species. Journal of the Bombay Natural History Society 80 : 176-179. 